\title{
Diffusion Tensor Imaging Correlates with the Clinical Assessment of Disease Severity in Cervical Spondylotic Myelopathy and Predicts Outcome following Surgery
}

J.G.A. Jones, S.Y. Cen, R.M. Lebel, P.C. Hsieh, and M. Law

\begin{abstract}
BACKGROUND AND PURPOSE: CSM is a common neurologic disease that results in progressive disability and eventual paralysis without appropriate treatment. Imaging plays a significant role in the evaluation of CSM and has evolved with recent technical advances. We sought to systematically explore the relationship between clinical disease severity and DTI in CSM, and to investigate the potential use of DTI in surgical decision-making models.
\end{abstract}

MATERIALS AND METHODS: MR imaging studies and clinical assessments were prospectively collected on 30 patients with CSM. Spearman correlations were used to investigate associations between clinical disease severity and FA at the time of diagnosis. Clinical assessment was performed using mJOA, Nurick, Short Form-36, and NDI scores. Fifteen patients with CSM subsequently underwent decompressive surgery; Spearman correlation and logistic regression were applied to this cohort to study the relationship between baseline DTI measurements and postoperative outcome. Conventional imaging (spinal cord T2 signal intensity and degree of stenosis) was evaluated for comparison with DTI.

RESULTS: At diagnosis, FA demonstrated a strong correlation with baseline mJOA $(r=0.62, P<.01)$ and Nurick $(r=-0.46, P=.01)$ scores. After surgery, recovery of function demonstrated by improvement in NDI score was associated with higher FA values on preoperative DTI $(r=-0.61, P=.04)$. Severely affected patients with CSM with disproportionately high FA tended to achieve greater mJOA scores after surgery compared with subjects with lower FA $(P=.08)$. T2 signal intensity was associated with functional status at baseline but did not predict postoperative outcome; degree of stenosis lacked any significant correlation with clinical parameters.

CONCLUSIONS: DTI may be a useful diagnostic tool for assessing disease severity in CSM. The predictive value of DTI regarding postoperative outcome may improve surgical decision-making and facilitate health care outcomes research.

ABBREVIATIONS: CSM = cervical spondylotic myelopathy; $\mathrm{DCSA}=$ dural cross-sectional area; $\mathrm{FA}=$ fractional anisotropy; $\mathrm{mJOA}=$ modified Japanese Orthopedic Association; NDI = Neck Disability Index; ROC = receiver operating characteristic; SF-36 = Short Form-36; SI = signal intensity

$\mathbf{C}_{\mathrm{s}}^{\mathrm{s}}$ M is characterized by spontaneous degeneration of the paraspinal bone, ligament, and intervertebral disk. ${ }^{1}$ It occurs in $60 \%$ of the population aged 40 and older. ${ }^{2}$ Progressive narrowing of the spinal canal induces myelopathy through direct compression, ischemia, and other pathologic processes affecting the spinal cord. ${ }^{3}$ Recent reports suggest that DTI may serve as a biomarker

Received February 24, 2012; accepted after revision April 16.

From the Departments of Radiology (J.G.A.J., M.L.) and Neurological Surgery (P.C.H.), USC Keck School of Medicine; Department of Biokinesiology \& Physical Therapy (S.Y.C.), Herman Ostrow School of Dentistry of USC; and Ming Hsieh Department of Electrical Engineering (R.M.L.), USC Viterbi School of Engineering, Los Angeles, California.

Portions of this research previoulsy presented at: Annual Meeting of the Radiological Society of North America, November 29, 2011; Chicago, Illinois.

Please address correspondence to Jesse G.A. Jones, Department of Radiology, USC Keck School of Medicine, 1520 San Pablo St, HCC2, Lower Level, Los Angeles, CA, 90033; e-mail: jessejon@usc.edu

http://dx.doi.org/10.3174/ajnr.A3199 of spinal cord injury associated with CSM. ${ }^{4-7}$ DTI parameterizes water diffusion within tissues and reports, among other metrics, the FA of the diffusion. FA represents an estimate of the directionality of water diffusion at the voxel level. Highly oriented axonal membranes and myelin sheaths are believed to produce highly anisotropic diffusion. ${ }^{8}$ Long tract demyelination and atrophy have been shown to reduce FA, as water diffuses more readily across damaged axonal membranes than it does across intact membranes and myelin sheaths. ${ }^{9,10}$

Theoretically, DTI appears well suited to evaluate the axonal pathology underlying CSM. Yet it still must be validated before providing significant utility for treating clinicians. Current anatomic imaging often reveals findings discordant with patients' functional status, thereby creating a management dilemma. ${ }^{11-15}$ For instance, spinal stenosis may represent benign age-related spondylosis in an otherwise healthy person, whereas, in another person, it may represent the focus of progressive myelopathy. Im- 
Table 1: Subject demographics

\begin{tabular}{|c|c|c|c|c|}
\hline Characteristic & $\begin{array}{l}\text { All Subjects } \\
\text { (Mean } \pm \text { SD) }\end{array}$ & $\begin{array}{l}\text { Surgery Cohort } \\
\text { (Mean } \pm \text { SD) }\end{array}$ & $\begin{array}{c}\text { Nonsurgery Cohort } \\
\text { (Mean } \pm \text { SD) }\end{array}$ & $\begin{array}{c}P \\
\text { Value }\end{array}$ \\
\hline Age (years) & $61.89 \pm 12.37(n=30)$ & $61.49 \pm 9.63(n=15)$ & $62.28 \pm 14.96(n=15)$ & .79 \\
\hline \multicolumn{5}{|l|}{ Sex } \\
\hline Female & $16(53.3 \%)$ & $6(40 \%)$ & $10(66.7 \%)$ & .14 \\
\hline Male & $14(46.7 \%)$ & $9(60 \%)$ & $5(33.3 \%)$ & \\
\hline Follow-up (days) & & $180.67 \pm 103.35(n=15)$ & & \\
\hline Baseline SF-36 (MCS) & $6.86 \pm 13.23(n=27)$ & $12.64 \pm 13.2(n=13)$ & $1.49 \pm 11.16(n=14)$ & .03 \\
\hline Baseline SF-36 (PCS) & $14.73 \pm 11.17(n=27)$ & $15.75 \pm 10.88(n=13)$ & $13.77 \pm 11.76(n=14)$ & .59 \\
\hline Baseline NDI & $35.96 \pm 19.19(n=27)$ & $36.62 \pm 17.42(n=13)$ & $35.36 \pm 21.28(n=14)$ & .92 \\
\hline Baseline Nurick & $1.7 \pm 1.51(n=30)$ & $2.2 \pm 1.7(n=15)$ & $1.2 \pm 1.15(n=15)$ & .11 \\
\hline Baseline mJOA & $13.67 \pm 2.83(n=30)$ & $12.4 \pm 3.04(n=15)$ & $14.93 \pm 1.98(n=15)$ & .02 \\
\hline $\mathrm{FAC}-\mathrm{C} 3$ & $0.64 \pm 0.07(n=30)$ & $0.6 \pm 0.07(n=15)$ & $0.69 \pm 0.05(n=15)$ & $<.01$ \\
\hline FA stenosis level & $0.51 \pm 0.1(n=30)$ & $0.47 \pm 0.09(n=15)$ & $0.55 \pm 0.1(n=15)$ & .05 \\
\hline FA C7-T1 & $0.52 \pm 0.07(n=30)$ & $0.51 \pm 0.09(n=15)$ & $0.53 \pm 0.06(n=15)$ & .4 \\
\hline High T2 SI & $9(30 \%)$ & $7(46.7 \%)$ & $2(13.3 \%)$ & .05 \\
\hline $\mathrm{DCSA}(\mathrm{mm})$ & $107.61 \pm 22.03(n=30)$ & $106.43 \pm 24.82(n=15)$ & $108.8 \pm 19.65(n=15)$ & .77 \\
\hline
\end{tabular}

Note:-MCS indicates mental component score; PCS, physical component score.
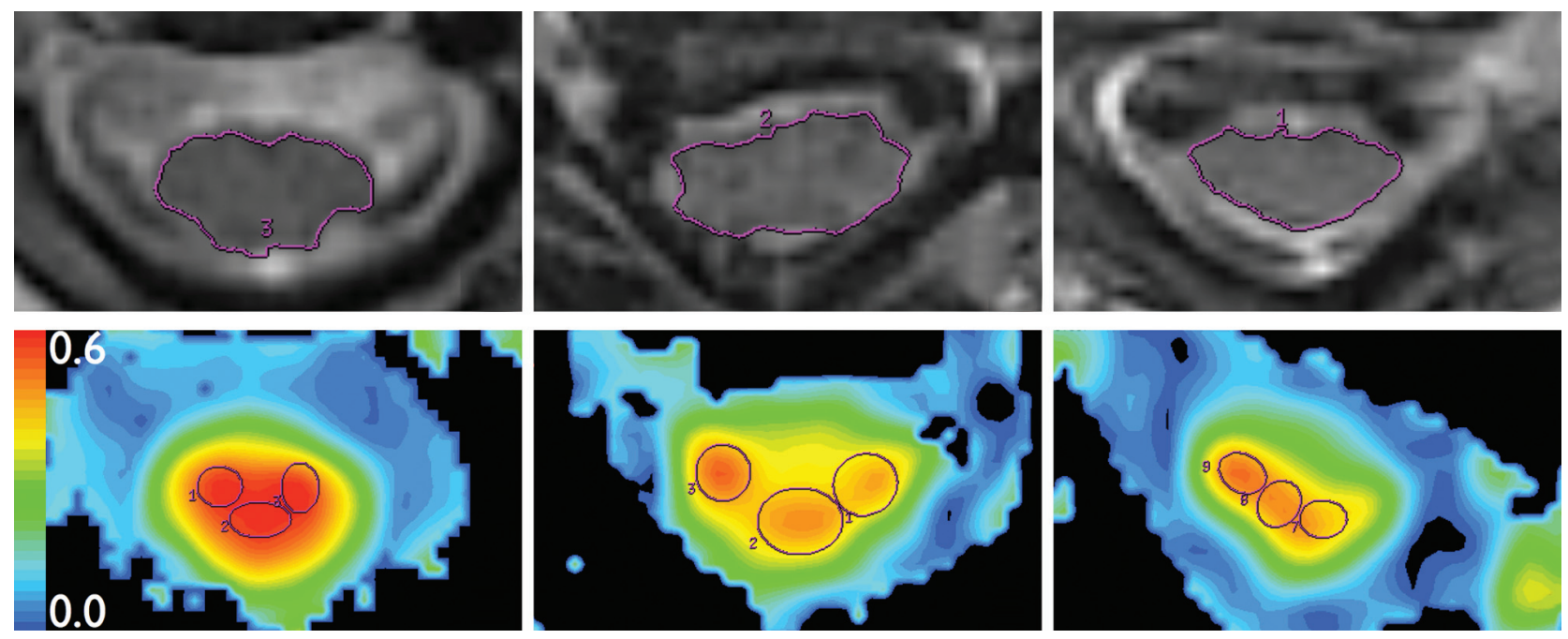

FIG 1. Region-of-interest placement. Top: Spinal cord area is measured on axial T2WI images (TR $=3250 \mathrm{~ms} ; \mathrm{TE}=127 \mathrm{~ms} ;$ noncontrast) at C2-C3 (left), stenosis (center), and C7-Tl (right). Bottom: Three isometric ROls are placed onto FA colormaps from DTI (TR = $8100 \mathrm{~ms}$, TE $=94 \mathrm{~ms}$; noncontrast), same sections as Top. For each section, the 3 ROls comprise $70 \%$ of spinal cord area.

aging that clearly differentiates these patterns would greatly improve diagnostic confidence.

Researchers have also suggested that, by assessing spinal cord integrity, DTI may assist with clinical decision-making. ${ }^{5,16}$ However, the usefulness of DTI rests on anchoring metrics such as FA to physical examination findings as well as patients' quality of life. Anchor-based approaches are commonly used and accepted methods for investigating a new measurement based on existing outcomes (eg, FA values based on patients' perceived outcome after surgery). ${ }^{17}$ Contextualizing DTI with respect to such outcomes would serve to establish a biomarker for CSM, a disease without feasible access to tissue histology. In addition, anchoring would enable radiology-based health care outcomes research into therapeutic efficacy. This method of analysis is presently lacking in the CSM literature.

We hypothesize that a strong agreement exists between DTI and clinical disease severity in cervical spondylotic myelopathy. This work provides evidence supporting the use of DTI in routine diagnostic imaging of CSM. In addition, we investigate the correlation between physical examination findings and postsurgical outcomes to FA. The latter aim of identifying patients who may benefit from surgical intervention has important implications for managing CSM and for potentially reducing health care expenses.

\section{MATERIALS AND METHODS \\ Subjects}

The study was conducted with approval from the institutional review board and in compliance with the Health Insurance Portability and Accountability Act. Thirty patients with CSM (14 male, 16 female; mean age 62 years, range $37-83$ years) were prospectively studied between April 2010 and July 2011 (Table 1). Baseline functional status was assessed with Nurick, mJOA, NDI, and SF-36 scoring instruments at the initial office visit. Patients underwent MR imaging of the cervical spine within 50 days of their first appointment. All subjects were used in the anchoring analysis.

Fifteen of these subjects subsequently underwent decompressive surgery and were reassessed clinically to determine postoperative outcome. DTI was not performed postoperatively due to extensive imaging artifact imparted by surgical hardware. Surgical 
Table 2: Spearman correlation coefficients relating baseline clinical scores and fractional anisotropy in various regions of the spinal cord

\begin{tabular}{lcccc}
\hline $\begin{array}{c}\text { Anatomic } \\
\text { Region }\end{array}$ & $\begin{array}{c}\text { Clinical } \\
\text { Measure }\end{array}$ & $\begin{array}{c}\text { Spearman } \\
\text { Correlation }\end{array}$ & $\begin{array}{c}\boldsymbol{P} \\
\text { Value }\end{array}$ & $\boldsymbol{n}$ \\
\hline C2-C3 & mJOA & $0.62^{\mathrm{a}}$ & $<.01^{\mathrm{a}}$ & $30^{\mathrm{a}}$ \\
& Nurick & $-0.46^{\mathrm{a}}$ & $.01^{\mathrm{a}}$ & $30^{\mathrm{a}}$ \\
& SF-36 (MCS) & -0.26 & .19 & 27 \\
& SF-36 (PCS) & -0.27 & .17 & 27 \\
Level of stenosis & NDI & -0.19 & .35 & 27 \\
& mJOA & $0.47^{\mathrm{a}}$ & $<.01^{\mathrm{a}}$ & $30^{\mathrm{a}}$ \\
& Nurick & -0.25 & .18 & 30 \\
& SF-36 (MCS) & -0.09 & .64 & 27 \\
& SF-36 (PCS) & 0.21 & .29 & 27 \\
C7-T1 & NDI & 0.19 & .35 & 27 \\
& mJOA & 0.31 & .09 & 30 \\
& Nurick & $-0.38^{\mathrm{a}}$ & $.04^{\mathrm{a}}$ & $30^{\mathrm{a}}$ \\
& SF-36 (MCS) & -0.02 & .92 & 27 \\
& SF-36 (PCS) & 0.01 & .96 & 27 \\
& NDI & -0.03 & .89 & 27 \\
\hline
\end{tabular}

Note:-MCS indicates mental component score; PCS, physical component score. ${ }^{a}$ Indicates values are statistically significant.

subjects were followed from initial office visit to the termination of the study. Mean postoperative follow-up time was 181 days (range 59-373 days).

\section{Clinical Assessment}

Subjects were treated by a fellowship-trained, board-certified neurosurgeon (P.C.H.) and received standard of care management for CSM. No specific threshold regarding the degree of myelopathy determines conservative treatment versus surgery. Indi-
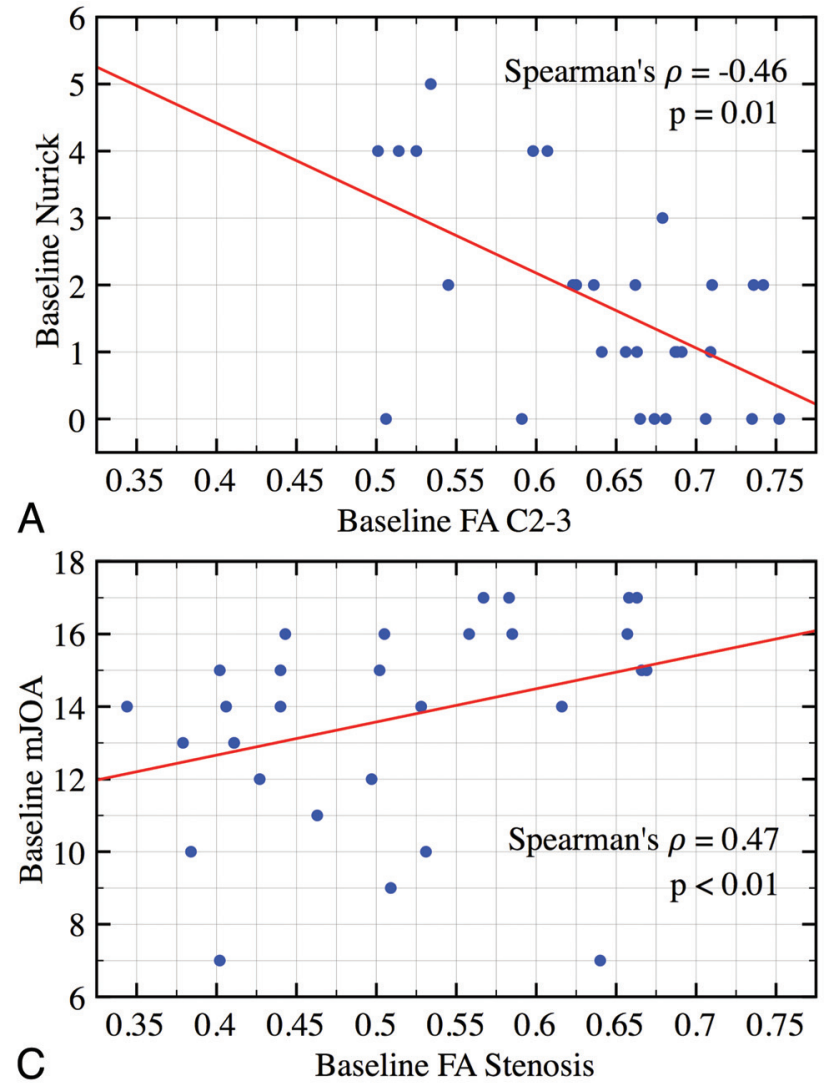

cations to perform surgery include moderate and severe myelopathy symptoms, progressive neurologic deterioration, severe cord compression, and spinal instability. Patients are offered conservative treatment if they exhibit either mild, stable myelopathy symptoms or only long tract signs with minimal myelopathy on neurologic examination, or if they have moderate canal stenosis and mild CSM. At each office visit, the degree of myelopathy was assessed with the mJOA and Nurick scales, while functional and pain outcomes were assessed with SF-36 score and NDI. mJOA provides a quantitative assessment of function by evaluating the ability to use one's hands, ambulate, and void, whereas Nurick focuses on gait. ${ }^{18,19}$ Both mJOA and Nurick scores were calculated from the study neurosurgeon's history and physical examination report by an investigator blinded to imaging results. NDI is a 10 -item scaled questionnaire completed by the patient, who focuses on activities of daily living. ${ }^{20}$ SF-36 is a multipurpose, short-form health survey completed by the patient. It yields an 8 -scale profile of functional health and well-being, psychometrically based physical and mental health summaries, and a preference-based health utility index..$^{21-23}$

\section{Imaging}

MR imaging of the cervical spine was performed on a 3T HDxt scanner (GE Healthcare, Milwaukee, Wisconsin) with a dedicated cervical spine coil. Standard sagittal T1WI $(\mathrm{TR}=700 \mathrm{~ms}$; $\mathrm{TE}=$ $11.7 \mathrm{~ms} ; \mathrm{FOV}=\mathrm{cm}^{2}$; matrix $=256 \times 320$; section thickness $=3$ $\mathrm{mm}), \mathrm{T} 2 \mathrm{WI}\left(\mathrm{TR}=4350 \mathrm{~ms} ; \mathrm{TE}=130 \mathrm{~ms} ; \mathrm{FOV}=52.4 \times 24 \mathrm{~cm}^{2}\right.$; matrix $=384 \times 384$; section thickness $=3 \mathrm{~mm}$ ), short $\tau$ inversion
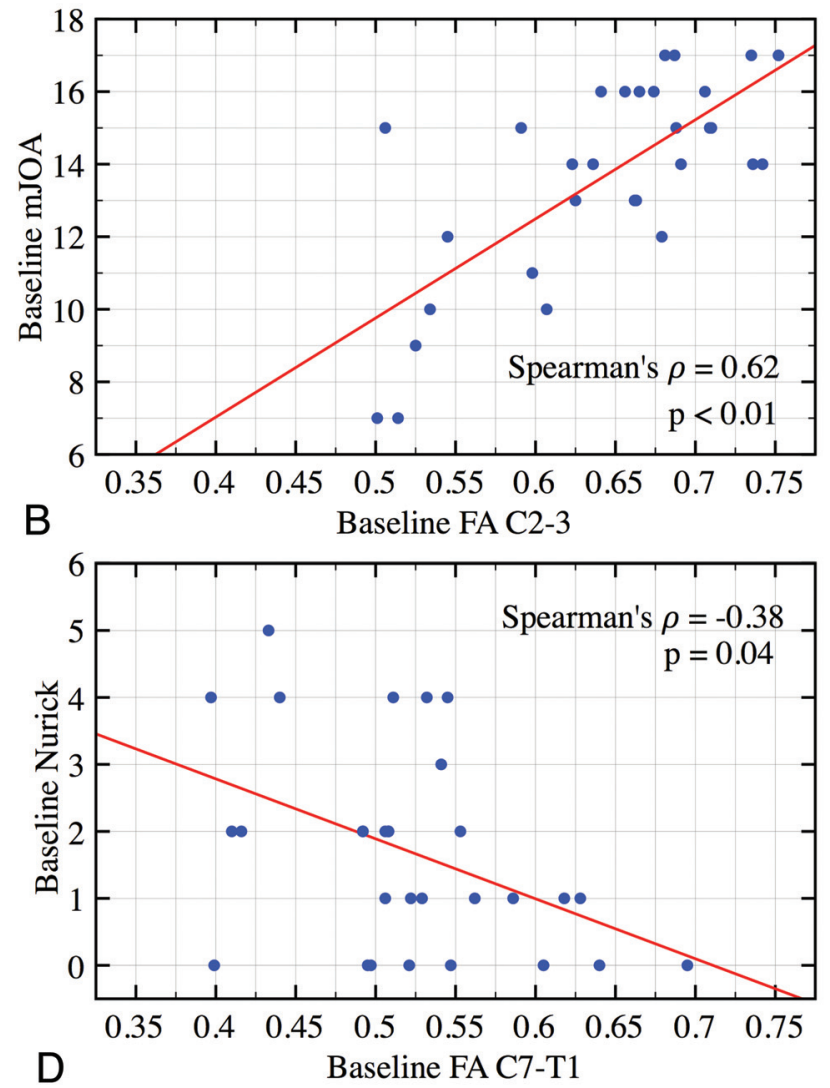

FIG 2. Correlation plots of baseline physical examination score and FA for all 30 subjects. A strong and significant correlation is observed between Nurick and mJOA scores and FA values at C2-C3 (upper panels), stenosis (bottom left), and C7-T1 (bottom right). 
Table 3: Associations between T2 SI and baseline and postoperative clinical scores

\begin{tabular}{|c|c|c|c|}
\hline $\begin{array}{l}\text { Baseline Clinical } \\
\text { Score }\end{array}$ & $\begin{array}{l}\text { High T2 SI } \\
\quad(n=9)\end{array}$ & $\begin{array}{c}\text { Normal T2 SI } \\
\quad(n=21)\end{array}$ & $\begin{array}{c}P \\
\text { Value }\end{array}$ \\
\hline \multicolumn{4}{|l|}{ MJOA } \\
\hline Mean \pm SD & $11.33 \pm 3.43^{\mathrm{a}}$ & $14.67 \pm 1.85^{a}$ & $.01^{\mathrm{a}}$ \\
\hline Median (Q1-Q3) & $11(9-15)^{a}$ & $15(14-16)^{a}$ & \\
\hline \multicolumn{4}{|l|}{ SF-36 (MCS) } \\
\hline Mean $\pm S D$ & $5.95 \pm 11.47$ & $7.24 \pm 14.18$ & .82 \\
\hline Median (Q1-Q3) & $5(-3.45-14.65)$ & $9.2(-4.1-17.8)$ & \\
\hline \multicolumn{4}{|l|}{ NDI } \\
\hline Mean $\pm S D$ & $42.63 \pm 22.23$ & $33.16 \pm 17.6$ & .25 \\
\hline Median (Q1-Q3) & $52(24-54)$ & $34(22-42)$ & \\
\hline \multicolumn{4}{|l|}{ Nurick } \\
\hline Mean $\pm S D$ & $3 \pm 1.32^{a}$ & $1.14 \pm 1.24^{a}$ & $<.01^{\mathrm{a}}$ \\
\hline Median (Q1-Q3) & $4(2-4)^{a}$ & $1(0-2)^{a}$ & \\
\hline \multicolumn{4}{|l|}{ SF-36 (PCS) } \\
\hline Mean $\pm S D$ & $19.55 \pm 12.72$ & $12.69 \pm 10.13$ & .15 \\
\hline Median (Q1-Q3) & 21.35 (14.45-29.05) & $9.6(5-23.9)$ & \\
\hline \multicolumn{4}{|c|}{$\begin{array}{l}\text { Change in Clinical Score } \\
\text { (following surgery) }\end{array}$} \\
\hline \multicolumn{4}{|l|}{ MJOA } \\
\hline Mean \pm SD & $1.86 \pm 1.35$ & $1.38 \pm 1.3$ & .44 \\
\hline Median (Q1-Q3) & $2(1-3)$ & $1(0.5-2)$ & \\
\hline \multicolumn{4}{|l|}{ Nurick } \\
\hline Mean \pm SD & $-0.86 \pm 0.69$ & $-0.25 \pm 0.46$ & .07 \\
\hline Median (Q1-Q3) & $-1(-1-0)$ & $0(-0.5-0)$ & \\
\hline \multicolumn{4}{|l|}{ SF-36 (MCS) } \\
\hline Mean $\pm S D$ & $2.03 \pm 10.24$ & $-10.39 \pm 9.9$ & .06 \\
\hline Median (Q1-Q3) & $0(-3.6-2.5)$ & $-8.1(-17.4-0)$ & \\
\hline \multicolumn{4}{|l|}{ SF-36 (PCS) } \\
\hline Mean $\pm S D$ & $-0.3 \pm 7.67$ & $0.24 \pm 5.24$ & .88 \\
\hline Median (Q1-Q3) & $0(-5.3-1.4)$ & $0(-2.5-0)$ & \\
\hline \multicolumn{4}{|l|}{ NDI } \\
\hline Mean $\pm S D$ & $-1 \pm 27.36$ & $-2 \pm 11.2$ & .67 \\
\hline Median (Q1-Q3) & $8(-34-18)$ & $0(-10-6)$ & \\
\hline
\end{tabular}

Note:-MCS indicates mental component score; PCS, physical component score. a Indicates values are significant

recovery $(\mathrm{TR}=4350 \mathrm{~ms} ; \mathrm{TE}=48.5 \mathrm{~ms} ; \mathrm{TI}=160 \mathrm{~ms} ; \mathrm{FOV}=52.4$ $\times 24 \mathrm{~cm}^{2}$; matrix $=256 \times 256$; section thickness $=3 \mathrm{~mm}$ ), and axial T1WI $\left(\mathrm{TR}=600 \mathrm{~ms} ; \mathrm{TE}=11.9 \mathrm{~ms} ; \mathrm{FOV}=39.3 \times 18 \mathrm{~cm}^{2}\right.$; matrix $=256 \times 192$; section thickness $=3.5 \mathrm{~mm})$ and $\mathrm{T} 2 \mathrm{WI}$ $\left(\mathrm{TR}=3250 \mathrm{~ms} ; \mathrm{TE}=127 \mathrm{~ms} ; \mathrm{FOV}=39.3 \times 18 \mathrm{~cm}^{2} ;\right.$ matrix $=$ $256 \times 256$; section thickness $=3.5 \mathrm{~mm}$ ) sequences were acquired. In addition, DTI was performed using a single-shot echo-planar imaging sequence with 6 diffusion directions, each encoded with $b=1000 \mathrm{~mm}^{2} / \mathrm{s}$ and a $b=0 \mathrm{~mm}^{2} / \mathrm{s}$ image. Imaging parameters were $\mathrm{TR}=8100 \mathrm{~ms}, \mathrm{TE}=94.1 \mathrm{~ms}, \mathrm{FOV}=18 \times 18 \mathrm{~cm}^{2}$, matrix $=$ $128 \times 128$ (phase-encoding anterior/posterior). The bandwidth in the frequency direction was $1953 \mathrm{~Hz} /$ pixel. Twenty-four contiguous transverse $4-\mathrm{mm}$ thick sections were acquired. Scan time for the DTI protocol was 3 minutes, 55 seconds; total scan time was 33 minutes, 13 seconds.

\section{Image Analysis}

Raw DTI data were postprocessed off-line using an Advantage workstation (ADW 4.0; GE Healthcare) to create FA maps of 3 axial sections: at C2-C3, at the level of most severe stenosis, and at C7-T1. Image registration was performed with eddy current correction. Measurements were performed by a single board-certified, fellowship-trained neuroradiologist with 15 years' experience (M.L.). At each of the 3 sections examined, spinal cord area was determined on the matching T2 axial section. Seventy percent of the area was then incorporated into 3 isometric regions of interest drawn over the spinal cord (right, center, left) on FA maps (Fig 1). The maximum average FA value was then selected for analysis. Interobserver and intraobserver coefficients of variation of $30 \%$ and $32 \%-41 \%$, respectively, have been reported for this technique. $^{24}$

Conventional imaging was also reviewed for evidence of CSM using 2 common metrics: abnormal spinal cord signal on T2 and degree of spinal stenosis. The presence of high SI on T2-weighted axial or sagittal images of the cervical spinal cord denoted a positive finding, whereas lack of high SI was considered negative. ${ }^{25,26}$ Spinal stenosis was assessed by measuring DCSA at the level of worst stenosis on T2-weighted axial images. ${ }^{27}$

\section{Statistical Analysis}

The Kolmogorov-Smirnov test was used to examine normality for all continuous measurements. All MR imaging measurements except C7-T1 FA were found to exhibit a normal distribution. However, no clinical score measurement fit a normal distribution. Baseline comparisons between surgery and nonsurgery groups were made using the $\chi^{2}$ test for categoric measurements (eg, sex) and Wilcoxon rank sum test for continuous measurements (eg, FA). Correlations between clinical and MR imaging measurements were examined using Spearman correlation for DTI and DCSA, and $t$ tests for T2 SI. The area under the ROC curve was used to assess and compare the prediction accuracy between DTI, T2 signal, DCSA, and mJOA. Length of follow-up and age at baseline evaluation were examined as potential confounders before performing the correlation analysis. By definition, a confounder must associate with both variables in the correlation analysis. ${ }^{28}$ We determined that length of follow-up was not a confounder. Conversely, age at baseline evaluation did correlate with both MR imaging measurements and change in clinical score after surgery, so partial Spearman correlation was used to control the confounding effect of age. Logistic regression was used to test the interaction between baseline clinical and MR imaging measurements in predicting the chance of achieving recovery of function.

\section{RESULTS}

DTI of the cervical spine with region-of-interest analysis was successfully performed in all patients. In most cases, extensive degenerative change resulted in multilevel CSM. All MR imaging measurements, except C7-T1 FA, were found to exhibit a normal distribution. However, no clinical score measurement fit a normal distribution. As described below, agreement was found between FA values from region-of-interest analysis of axial DTI data and baseline mJOA and Nurick scores. Of the 15 subjects who underwent surgery, a significant relationship was found between FA values and postoperative functional recovery assessed by NDI.

\section{Correlation with Initial Clinical Assessment Scores}

In patients with CSM, poor neurologic function, assessed with mJOA and Nurick scores, is associated with lower FA throughout the cervical spinal cord (Table 2, Fig 2). Interestingly, the most significant findings occurred at vertebral body levels lacking spinal stenosis on conventional T2WI. At C2-C3, FA correlated with 

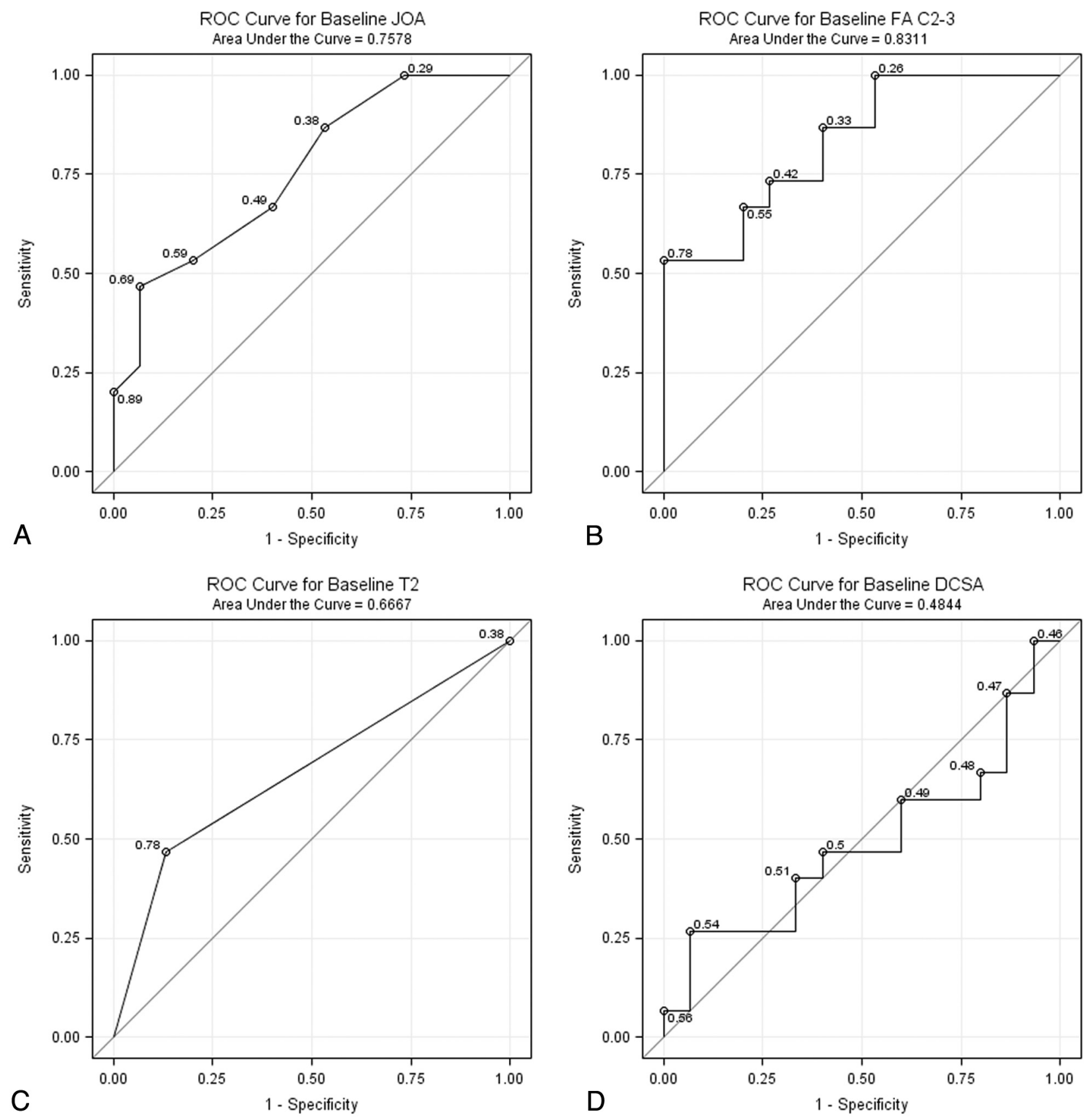

FIG 3. ROC curves demonstrating the accuracy of $(A)$ mJOA, (B) FA, $(C) \mathrm{T} 2 \mathrm{SI}$, and $(D)$ DCSA for predicting surgeon's decision to operate. DCSA possesses a significantly lower area under the curve compared with the other 3 metrics.

both mJOA $(r=0.62, P<.01)$ and Nurick $(r=-0.46, P=.01)$ scales. A similar pattern was demonstrated at the level of stenosis yet only reached significance with mJOA $(r=0.47, P=.01)$. Conversely, at C7-T1, Nurick reached significance $(r=-0.38$, $P=.04)$ and mJOA trended toward significance $(P=.09)$. No significant correlation was found between FA values and more subjective patient-centered scores, including NDI and SF-36. Based on mJOA and Nurick scores, CSM appears to severely affect subjects below a threshold FA of 0.62 at the C2-C3 level (Fig 2).

High T2 SI corresponded with poor neurologic status on baseline mJOA and Nurick scores. Similar to DTI results, this association failed to reach significance on patient-centered metrics ( $\mathrm{Ta}$ - ble 3). No significant association was found between DCSA and baseline clinical parameters.

\section{Relation to Surgical Outcome}

Fifteen subjects underwent surgical decompression for CSM, while the other 15 subjects were treated conservatively. Clinical myelopathy represents an operative indication, which is reflected by the finding that baseline mJOA scores in the surgical cohort were significantly lower than nonsurgical patients (Table 1). ${ }^{29} \mathrm{We}$ compared the accuracy of mJOA for predicting surgical decisionmaking to radiologic metrics such as FA, T2 SI, and DCSA using ROCs. FA was superior in predicting which patients eventually 


\begin{tabular}{|c|c|c|c|c|}
\hline $\begin{array}{c}\text { Anatomic } \\
\text { Region }\end{array}$ & $\begin{array}{c}\text { Clinical } \\
\text { Measure }\end{array}$ & $\begin{array}{l}\text { Spearman } \\
\text { Correlation }\end{array}$ & $\begin{array}{c}P \\
\text { Value }\end{array}$ & $n$ \\
\hline \multirow[t]{5}{*}{$\mathrm{C} 7-\mathrm{Tl}$} & $\mathrm{mJOA}$ & 0.02 & .93 & $\overline{15}$ \\
\hline & Nurick & 0.17 & .56 & 15 \\
\hline & SF-36 (MCS) & 0.1 & .76 & 13 \\
\hline & SF-36 (PCS) & -0.07 & .84 & 13 \\
\hline & NDI & 0.11 & .73 & 13 \\
\hline \multirow[t]{5}{*}{ Level of stenosis } & $\mathrm{mJOA}$ & 0.06 & .84 & 15 \\
\hline & Nurick & -0.22 & .44 & 15 \\
\hline & SF-36 (MCS) & 0.28 & .38 & 13 \\
\hline & SF-36 (PCS) & -0.21 & .51 & 13 \\
\hline & NDI & $-0.61^{\mathrm{a}}$ & $.04^{\mathrm{a}}$ & $13^{\mathrm{a}}$ \\
\hline \multirow[t]{5}{*}{$\mathrm{C} 2-\mathrm{C} 3$} & mJOA & -0.26 & .38 & 15 \\
\hline & Nurick & 0.17 & .56 & 15 \\
\hline & SF-36 (MCS) & -0.4 & .2 & 13 \\
\hline & SF-36 (PCS) & 0.1 & .75 & 13 \\
\hline & NDI & 0.36 & .25 & 13 \\
\hline
\end{tabular}

Note:-MCS indicates mental component score; PCS, physical component score. ${ }^{a}$ Indicates values are significant.

underwent surgery, though the difference in the area under the curve was only significant for DCSA (Fig 3).

Most (93\%) patients with CSM improved on at least 1 assessment scale after surgery. No patient declined neurologically, yet the extent of recovery varied. Higher baseline FA correlated with improvement in NDI after surgery $(P=.04$; Table 4$)$. This association was absent for physical-examination-centered metrics such as Nurick and mJOA scales. However, logistic regression analysis showed a trend toward different prediction weights for FA in high, compared with low, baseline mJOA score $(P=.08)$. Severely affected patients with CSM with disproportionately high FA values tended to possess a greater chance of achieving functional recovery after surgery than those exhibiting low FA values. For an mJOA score of 8/15, each 0.1 increment in FA increases the chance of making a clinical improvement by 1.5 times (95\% CI; $0.1,42.5)$. This trend was not observed in patients with high mJOA scores. Baseline clinical scores were not predictive of postoperative outcome in any of the assessment measures.

A significantly greater proportion of subjects with high T2 SI underwent surgery compared with those with normal SI (Table 1), yet no relationship was found between T2 signal and postoperative recovery (Table 4). DCSA possessed no significant association with any outcome measure.

\section{DISCUSSION}

DTI has been found to detect differences in clinically symptomatic patients with CSM with greater sensitivity and specificity than conventional MR imaging. ${ }^{2,30}$ However, establishing health care utility requires further work in anchoring DTI metrics to validated clinical assessment tools. Here, we have quantified the strength of the relationship between FA values and baseline neurologic status. In addition, we have shown that FA predicts who will undergo surgery and what degree of clinical improvement they will gain.

DTI shows promise for becoming an integral part of the diagnostic imaging work-up for CSM., ${ }^{2,45}$ Although CSM remains a clinical diagnosis, DTI may add value in assessing disease severity and influence the treatment plan. Early stage myelopathy presents with subtle physical examination findings, whereas chronic CSM often coexists with lumbar spine disease, which muddles clinician assessments. Conventional imaging adds further confusion when findings are disparate to patient functional status, as with DCSA results described here and elsewhere. ${ }^{2,31}$ DTI can increase diagnostic confidence by identifying the location of spinal cord injury and quantifying its severity. In practice, the relationship between FA and surgical decision-making (Fig 3) may help the referring primary care physician determine whether his or her patient with CSM requires neurosurgical consultation.

We report similar clinical-imaging correlations for DTI and T2 SI, which is not surprising, given that both imaging sequences are sensitive to spinal cord edema. However, this study demonstrates several advantages of DTI that may warrant its inclusion into standard protocols. FA values serve as a biomarker for long tract function ranging from healthy states to severe myelopathy. When treated as a continuous variable, FA may provide more precise characterization of CSM than binary measures like the presence or absence of high T2 SI. For instance, clinical suspicion
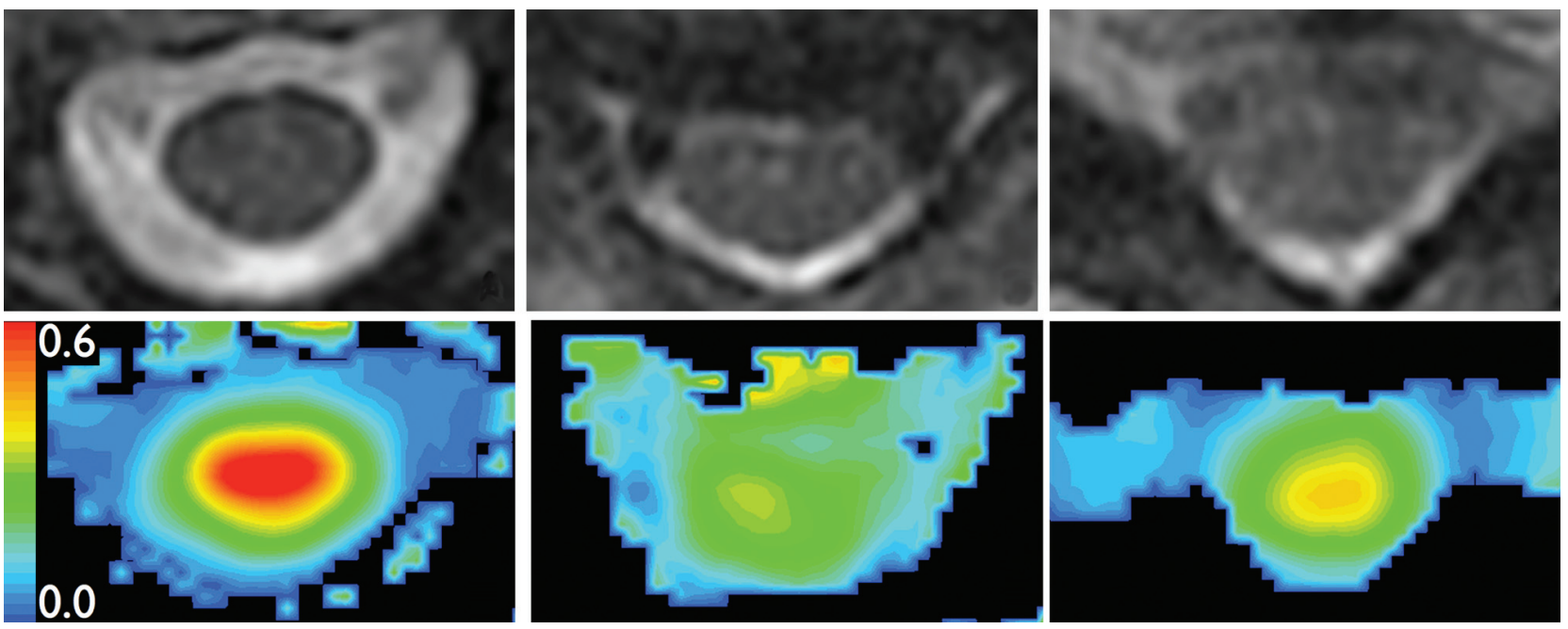

FIG 4. MR imaging of subject A. Top: Axial T2WI (TR = $3250 \mathrm{~ms} ; \mathrm{TE}=127 \mathrm{~ms}$; noncontrast) at C2-C3 (left), stenosis (center), and C7-T1 (right). Bottom: FA colormaps from DTI (TR $=8100 \mathrm{~ms}$, TE $=94 \mathrm{~ms}$; noncontrast), same sections as Top. 

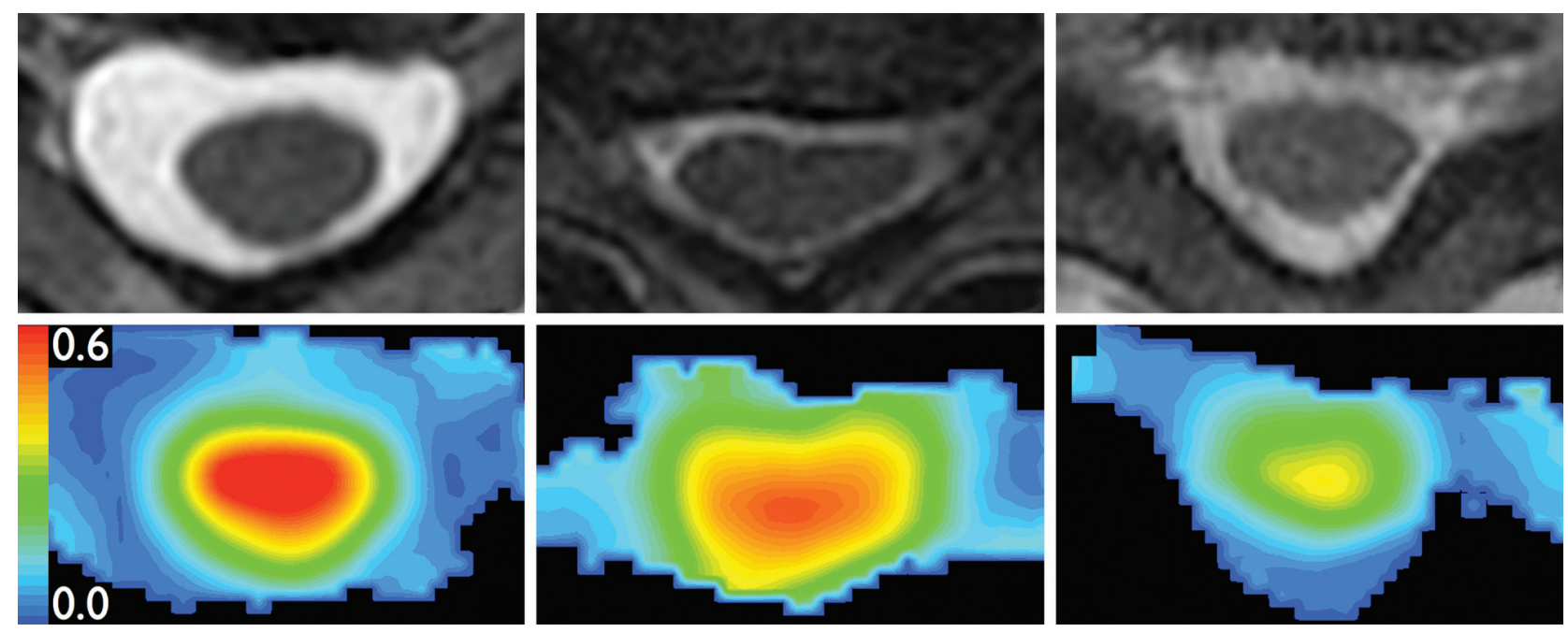

FIG 5. MR imaging of subject $B$. Top: Axial T2WI (TR = $3250 \mathrm{~ms}$; TE $=127 \mathrm{~ms}$; noncontrast) at C2-C3 (left), stenosis (center), and C7-T7 (right). Bottom: FA colormaps from DTI (TR $=8100 \mathrm{~ms}$, TE $=94 \mathrm{~ms}$; noncontrast), same sections as Top.

of myelopathy may prompt a DTI examination that identifies abnormalities before the development of high T2 SI.

Results from the surgery cohort reveal that high baseline FA is correlated with postoperative functional recovery (Table 3). Controlling for potential confounders and using nonparametric statistics limited the power of our outcomes analysis. Nevertheless, logistic regression shows an intriguing discordance between baseline clinical and MR imaging measurements in subjects who later achieved a high level of functional recovery. This finding is exemplified by subject A (Fig 4), who possessed a relatively high baseline mJOA score of 15 yet a low FA of 0.506 . The subject achieved only modest improvement after surgery. In contrast, subject B (Fig 5) had a worse baseline mJOA score of 13 but a higher FA of 0.662. Subject B improved to a greater extent, reaching the same postoperative mJOA score of 17 as subject A. This suggests that FA may serve as a useful predictor of outcome.

By demonstrating that FA is anchored to discrete clinical states, this preliminary study serves as a basis for future work to determine the amount of signal loss due to reversible versus irreversible spinal cord injury. Specifically, the hypothesis that certain FA thresholds, in conjunction with baseline function, determine recovery potential after surgery warrants evaluation. This information may eventually be incorporated into surgical decisionmaking models. For instance, patients with a high likelihood of recovery may opt for intervention, whereas those with a low likelihood might choose watchful waiting. Such a model would minimize unnecessary surgeries, ration health care resources, and reduce costs. Expected improvement predicated on FA may also serve as an outcome measure for performance-based reimbursement and in clinical trials assessing novel procedures or instrumentation.

\section{Limitations}

We anticipated FA in the region of stenosis to provide the strongest correlation with disease severity; however, we observed that FA at C2-C3 was most strongly correlated. We believe this is an imaging artifact, as the stenotic region is highly distorted in the EPI readout and provides inconsistent DTI parameters. The cer- vical canal is wide at C2-C3 and remains free of osteophytes and calcified ligament that can degrade the image at the level of stenosis. Abnormal FA values at $\mathrm{C} 2-\mathrm{C} 3$ have been reported previously $^{4,16}$ and may represent wallerian degeneration that has spread from a more caudal area of stenosis. ${ }^{32}$ Therefore, C2-C3 may be a useful region of interest in the population of patients with CSM. Improvements in diffusion pulse sequences, such as reduced field-of-view implementations, may allow for superior assessment of stenotic regions in the future. ${ }^{33,34}$ Further studies with larger sample sizes, including a control population, are needed to validate threshold FA values indicative of disease severity and outcome. Differences in equipment, image acquisition, and processing across institutions pose additional challenges, and centers may need to develop their own reference range for DTI metrics.

\section{CONCLUSIONS}

FA values were significantly correlated with frequently used clinical assessment measures for CSM. In addition to serving as a diagnostic instrument, DTI predicts some aspects of functional recovery after surgery and may therefore have a role in decisionmaking models. Anchoring DTI metrics to more global qualityof-life measures may facilitate health care outcomes research into cost reduction, resource utilization, and improvements in patient care. A randomized, controlled trial with a larger sample size is needed to confirm these preliminary results.

\section{ACKNOWLEDGMENTS}

We thank medical students Thomas Chong and Amy Cummings for their assistance with data collection and revision of this manuscript.

Disclosures: Patrick Hsieh—UNRELATED: Consultancy: Medtronic Spine and Depuy Spine; Grants/Grants Pending: Depuy Spine;* Payment for Lectures (including service on speakers bureaus): Medtronic Spine and Depuy Spine. Meng Law — RELATED: Grant: NIH; ${ }^{*}$ Consulting Fee or Honorarium: Bayer, iCAD, Bracco, Toshiba; Fees for Participation in Review Activities such as Data Monitoring Boards, Statistical Analysis, Endpoint Committees, and the Like: Bayer; UNRELATED: Stock/Stock Options: Prism Clinical Imaging. ( ${ }^{*}$ Money paid to institution)

AJNR Am J Neuroradiol 34:471-78 Feb 2013 www.ajnr.org 


\section{REFERENCES}

1. Bernhardt M, Hynes RA, Blume HW, et al. Cervical spondylotic myelopathy. J Bone Joint Surg Am 1993;75:119-28

2. Boden SD, McCowin PR, Davis DO, et al. Abnormal magnetic-resonance scans of the cervical spine in asymptomatic subjects. A prospective investigation. J Bone Joint Surg Am 1990;72:1178-84

3. Levine DN. Pathogenesis of cervical spondylotic myelopathy. J Neurol Neurosurg Psychiatry 1997;62:334-40

4. Budzik J, Balbi V, Le Thuc V, et al. Diffusion tensor imaging and fibre tracking in cervical spondylotic myelopathy. Eur Radiol 2010;21:426-33

5. Kara B, Celik A, Karadereler S, et al. The role of DTI in early detection of cervical spondylotic myelopathy: a preliminary study with 3-T MRI. Neuroradiology 2011;53:609-16

6. Mamata H, Jolesz FA, Maier SE. Apparent diffusion coefficient and fractional anisotropy in spinal cord: age and cervical spondylosisrelated changes. J Magn Reson Imaging 2005;22:38-43

7. Jones J, Lerner A, Kim PE, et al. Diffusion tensor imaging in the assessment of ossification of the posterior longitudinal ligament: a report on preliminary results in 3 cases and review of the literature. Neurosurg Focus 2011;30:E14

8. Beaulieu C. The basis of anisotropic water diffusion in the nervous system - a technical review. NMR Biomed 2002;15:435-55

9. Tsuchiya K, Katase S, Fujikawa A, et al. Diffusion-weighted MRI of the cervical spinal cord using a single-shot fast spin-echo technique: findings in normal subjects and in myelomalacia. $\mathrm{Neu}$ roradiology 2003;45:90-94

10. Song SK, Sun SW, Ramsbottom MJ, et al. Dysmyelination revealed through MRI as increased radial (but unchanged axial) diffusion of water. Neuroimage 2002;17:1429-36

11. Fernandez de Rota JJ, Meschian S, Fernandez de Rota A, et al. Cervical spondylotic myelopathy due to chronic compression: the role of signal intensity changes in magnetic resonance images. J Neurosurg Spine 2007;6:17-22

12. Suri A, Chabbra RP, Mehta VS, et al. Effect of intramedullary signal changes on the surgical outcome of patients with cervical spondylotic myelopathy. Spine J 2003;3:33-45

13. Hori M, Okubo T, Aoki S, et al. Line scan diffusion tensor MRI at low magnetic field strength: feasibility study of cervical spondylotic myelopathy in an early clinical stage. J Magn Reson Imaging 2006;23:183-88

14. Demir A, Ries M, Moonen CT, et al. Diffusion-weighted MR imaging with apparent diffusion coefficient and apparent diffusion tensor maps in cervical spondylotic myelopathy. Radiology 2003;229:37-43

15. Healy JF, Healy BB, Wong WH, et al. Cervical and lumbar MRI in asymptomatic older male lifelong athletes: frequency of degenerative findings. J Comput Assist Tomogr 1996;20:107-12

16. Kang M, Anderer E, Elliott R, et al. Diffusion tensor imaging of the spondylotic cervical spinal cord: a preliminary study of quantifiable markers in the evaluation for surgical decompression. Internet J Head Neck Surg 2011;5

17. Parker SL, Adogwa O, Paul AR, et al. Utility of minimum clinically important difference in assessing pain, disability, and health state after transforaminal lumbar interbody fusion for degenerative lumbar spondylolisthesis. J Neurosurg Spine 2011;14:598-604

18. Nurick $S$. The pathogenesis of the spinal cord disorder associated with cervical spondylosis. Brain 1972;95:87-100

19. Benzel EC, Lancon J, Kesterson L, et al. Cervical laminectomy and dentate ligament section for cervical spondylotic myelopathy. J Spinal Disord 1991;4:286-95

20. Vernon H, Mior S. The Neck Disability Index: a study of reliability and validity. J Manipulative Physiol Ther 1991;14:409-15

21. Ware JE, Sherbourne CD. The MOS 36-item short-form health survey (SF-36). I. Conceptual framework and item selection. Med Care 1992;30:473-83

22. King JT Jr, McGinnis KA, Roberts MS. Quality of life assessment with the medical outcomes study short form-36 among patients with cervical spondylotic myelopathy. Neurosurgery 2003:52:11320; discussion 121

23. King JT, Roberts MS. Validity and reliability of the Short Form-36 in cervical spondylotic myelopathy. J Neurosurg 2002;97:180-85

24. Wetzel SG, Cha S, Johnson G, et al. Relative cerebral blood volume measurements in intracranial mass lesions: interobserver and intraobserver reproducibility study. Radiology 2002;224:797-803

25. Wada E, Ohmura M, Yonenobu K. Intramedullary changes of the spinal cord in cervical spondylotic myelopathy. Spine (Phila $\mathrm{Pa}$ 1976) 1995;20:2226-32

26. Kang Y, Lee JW, Koh YH, et al. New MRI grading system for the cervical canal stenosis. AJR Am J Roentgenol 2011;197:W134-40

27. Henderson L, Kulik G, Richarme D, et al. Is spinal stenosis assessment dependent on slice orientation? A magnetic resonance imaging study. Eur Spine J 2011 [Epub ahead of print]

28. Mayrent SL. Epidemiology in Medicine. Boston: Lippincott Williams \& Wilkins; 1987:287-304

29. Law MD, Bernhardt M, White AA. Cervical spondylotic myelopathy: a review of surgical indications and decision making. Yale J Biol Med 1993;66:165-77

30. Kerkovský M, Bednarík J, Dušek L, et al. Magnetic resonance diffusion tensor imaging in patients with cervical spondylotic spinal cord compression: correlations between clinical and electrophysiological findings. Spine (Phila Pa 1976) 2012;37:48-56

31. Facon D, Ozanne A, Fillard $P$, et al. MR diffusion tensor imaging and fiber tracking in spinal cord compression. AJNR Am J Neuroradiol 2005;26:1587-94

32. Guleria S, Gupta RK, Saksena S, et al. Retrograde wallerian degeneration of cranial corticospinal tracts in cervical spinal cord injury patients using diffusion tensor imaging. $J$ Neurosci Res 2008;86:2271-80

33. Saritas EU, Cunningham $\mathrm{CH}$, Lee JH, et al. DWI of the spinal cord with reduced FOV single-shot EPI. Magn Reson Med 2008;60:468-73

34. Zaharchuk G, Saritas EU, Andre JB, et al. Reduced field-of-view diffusion imaging of the human spinal cord: comparison with conventional single-shot echo-planar imaging. AJNR Am J Neuroradiol 2011;32:813-20 